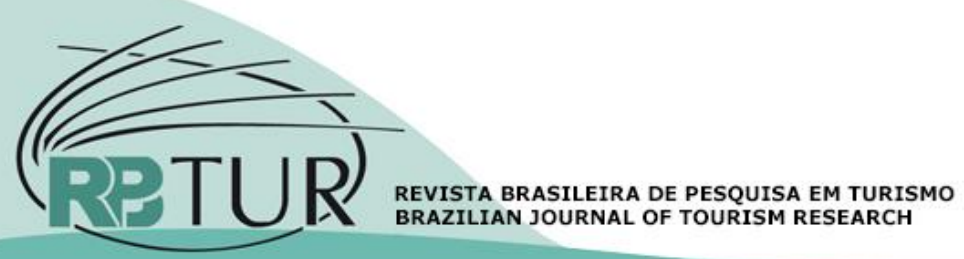

\title{
Artigos
}

\section{Governança em destinos turísticos: desafios na sociedade contemporânea}

\section{Governance in tourist destinations: challenges in a contemporary society}

\section{Gobernanza en destinos turísticos: desafíos en la sociedad contemporánea}

\author{
Ana Catarina Alves Coutinho1; Wilker Ricardo de Mendonça Nóbrega². \\ 1 Universidade Federal do Maranhão (UFMA), São Luís, Maranhão, Brasil \\ ¿Universidade Federal do Rio Grande do Norte (UFRN), Rio Grande do Norte, Brasil
}

\section{Palavras-chave:}

Governança;

Destinos turísticos;

Estado;

Redes.

Keywords:

Governance;

Tourist Destinations;

State;

Networks.

\section{Resumo}

A governança turística em destinos turísticos tem sido um tema amplamente debatido na literatura e apesar de preconizar diversos benefícios, estudos demonstram lacunas na sua constituição. Por isto, este trabalho tem como objetivo discutir os principais desafios para a construção da governança de destinos turísticos, a partir de uma análise conjuntural focada nos diferentes fatores sinalizados na literatura. Entende-se que em um contexto de busca de sustentabilidade dos destinos turísticos, faz-se necessário saber como geri-los, considerando suas fragilidades. Para tanto, utilizou-se a metodologia ProKnow-C, através de pesquisa em periódicos científicos tanto nacional como internacional, classificados pela Capes no escopo de A1 até B1. O estudo apresentou que os principais desafios da governança em destinos turísticos são divididos em dois tipos: institucionais e organizacionais. A primeira refere-se a questões associadas ao Estado e a segunda refere-se à relação entre os atores participantes da rede de governança em turismo. Conclui-se, desta forma, que os desafiosinstitucionais e organizacionais devem ser rompidos, visando uma leitura conjuntural e não estrutural das realidades.

\section{Abstract}

The topic of tourism governance in tourist destinations has been widely discussed in the literature and, although many benefits have been recognized, studies have shown that there are still structural gaps. Therefore, based on a conjunctural analysis of different factors identified in the literature, the objective of this paper is to discuss the main challenges of forming governance in tourist destinations. In order to understand how to preserve tourist destinations, understanding how to manage them, while also considering their weaknesses, is vital. To this end, this study used the ProKnow-C methodology, which involved a review of both domestic and international scientific journals that have a classification rating of between $B 1$ and $\mathrm{A} 1$ by Capes. The study revealed that the main challenges to governing tourist destinations can be divided into one of two categories: institutional and organizational. The former refers to issues related to the State, whereas the latter refers to the relationships among stakeholders who participate in tourism governance. Thus, we conclude that the institutional and organizational challenges should be broken in favour of a conjunctural and non-structural reading of realities. 
Palavras clave:

Gobernanza;

Destino Turistico;

Estado;

Redes.

Revisado por pares.

Recebido em: 20/10/2018.

Aprovado em: 08/05/2019.

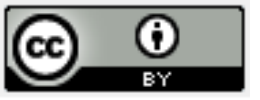

\begin{abstract}
Resumen
La gobernanza turística en destinos turísticos ha sido un tema ampliamente debatido en la literatura y, a pesar de preconizar diversos beneficios, estudios realizados demuestran lagunas en su constitución y, por eso, este trabajo tiene como objetivo principal, discutir los principales desafíos para la construcción de la gobernanza turismo en destinos, a partir de un análisis coyuntural enfocado en los diferentes factores señalados en la literatura. En este prisma, se comprende que, en un contexto de búsqueda de sostenibilidad de los destinos turísticos, se hace necesario saber cómo gestionarlos, fundamentalmente a considerar sus fragilidades. Para ello, se utilizó la metodología ProKnow-C para recolección de datos, a través de investigación en periódicos científicos, tanto nacionales como internacionales, clasificados por la Capes en el ámbito de A1 a B1. Como principales los resultados, se constató que el estudio presentó que los desafíos básicos de la gobernanza en destinos turísticos se dividen en dos tipos, que son: institucionales y organizacionales. La primera se refiere a cuestiones asociadas al Estado y la segunda se refiere a la relación entre los actores participantes de la red de gobernanza en turismo. Se concluye, de esta forma, que los desafíos institucionales y organizacionales deben ser rotos, buscando una lectura coyuntural y no estructural de las realidades.
\end{abstract}

Como citar: Coutinho A. C. A. \& Nóbrega, W. R. M. (2019). Governança em destinos turísticos: desafios na sociedade contemporânea. Revista Brasileira de Pesquisa em Turismo, São Paulo, 13 (3), p. 55 - 70, set./dez. http://dx.doi.org/10.7784/rbtur.v13i3.1543

\section{INTRODUÇÃO}

Tem se observado o crescente interesse científico nos estudos sobre governança turística nas últimas duas décadas (Caffyn \& Jobbin, 2003; Bramwell \& Sharman, 1999; Hall, 2011; Beaumont \& Dredge, 2010; Wan \& Bramwell, 2015), o que tem contribuído para uma melhor compreensão da nova organização social contemporânea, reforçada através dos laços de participação e articulação dos sujeitos responsáveis pelo processo de desenvolvimento do turismo regional.

O conceito não é novo, embora não exista um consenso quanto a sua definição, e por isso, comumente é confundido como sinônimo de governo. O conceito surgiu na década de 1970, através da crise de governabilidade, buscando entender se as novas estruturas administrativas, por meio dos seus processos, poderiam gerar consensos e soluções de conflitos.

De acordo com alguns autores (Hall, 2011; Velasco Gonzalez, 2013; Nóbrega \& Figueiredo, 2014; Wan \& Bramwell, 2015; Valente, Dredge \& Lohmann, 2015; Qian et al., 2016; Tretin, 2016), além da geração de consenso diante do cenário de conflitos, tem-se como benefício da governança turística a eficiência, a eficácia, a equidade, a transparência, a accountability, a cooperação e a legitimidade da participação social nas decisões coletivas por meio da democracia política com a representação de diversos interesses. Tais benefícios têm sido largamente difundidos e se tornado a tônica dos discursos políticos, sociais e empresariais.

Apesar de a governança turística sinalizar a possibilidade de uma série de benefícios, baseada em relações de cooperação, elas não estão desprendidas de relações de poder, que estão na essência da sociedade e organização estatal (Castells, 2000). 0 turismo, desta forma, impõe inúmeros desafios, em razão de suas peculiaridades, principalmente por se tratar de um fenômeno que ora tem interesses privados visando o lucro pessoal, ora necessita de ações compartilhadas, principalmente, no destino e entre destinos turísticos (Velasco Gonzalez, 2013).

Entende-se que em um contexto onde o discurso da sustentabilidade em destinos turísticos é tão presente, é necessário refletir acerca dos instrumentos de planejamento e gestão, envolvendo os interesses coletivos dos integrantes neste processo. Com base nesse propósito, este trabalho tem como objetivo discutir os principais desafios para a construção da governança nos destinos turísticos, a partir de uma análise conjuntural focada nos diferentes fatores, sinalizados na literatura.

Deste modo, o presente trabalho está dividido em quatro tópicos além desta introdução. A seção 2apresenta os procedimentos metodológicos para execução da pesquisa. A seção 3 discute a concepção do Estado e como seu comportamento, ao longo das últimas três décadas, tem refletido nos estudos sobre governança 
turística. Este cenário é compreendido como desafios institucionais, conforme elucidado na pesquisa. A quarta seção discute os conceitos de governança associado às noções de redes de atores e a forma como estes estão imbricados no processo face aos desafios da governança turística nos destinos turísticos. Este cenário é entendido como desafios organizacionais. Por fim, são apresentadas as considerações finais da pesquisa, elucidando algumas descobertas e incitando reflexões no sentido de possibilitar trabalhos futuros, sinalizando cenários positivos e debilidadesa partir do paradigma da sustentabilidade em destinos turísticos, tendo como alicerce, a discussãodo tema governança.

\section{DESENHO METODOLÓGICO DA PESQUISA}

Considerando a natureza do problema investigado, bem como o nível de aprofundamento, utilizou-se a pesquisa do tipo descritiva e exploratória, com abordagem qualitativa visto que esta é, particularmente, realizada quando o tema investigado é pouco explorado com a finalidade de desenvolver, esclarecer e modificar conceitos, buscando a formulação de respostas aos problemas complexos. A técnica foi baseada na pesquisa bibliográfica.

O estudo apresenta uma discussão teórica a cerca da governança turística em destinos turísticos, e para gerar um suporte às reflexões e a aproximação entre os temas foi definido o processo metodológico desenvolvido por Ensslin et al. (2010) denominado ProKnow-C - Knowledge Development ProcessConstructivist, que explicita as etapas da pesquisa estruturada em fases, conforme é destacado na Figura 01.

Figura 01. Procedimento ProKnow-C resumido para obtenção do portfólio bibliográfico

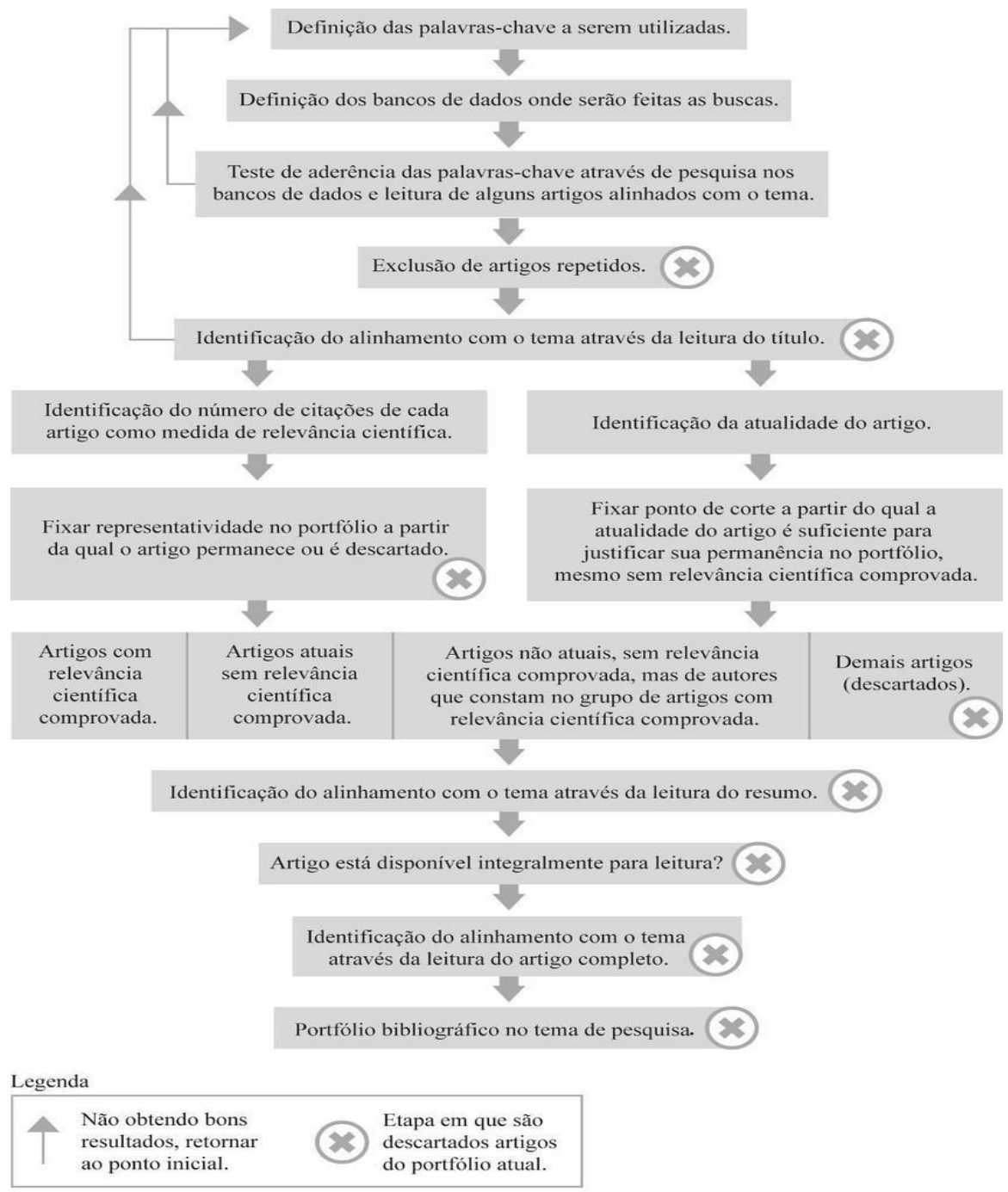


Fonte: Ensslin et al., 2010.

Para esta pesquisa adotou-se as seguintes palavras-chaves por esta imbricada no contexto do tema: governança, turismo, Estado, política pública e redes, que foram pesquisadas nos idiomas português, inglês e espanhol. As palavras foram utilizadas nos mecanismos de busca de artigos científicos, tanto de forma isolada, quanto de forma combinada, durante o período de agosto a novembro de 2017 para a coleta de dados. 0 teste de aderência foi utilizado, confirmando a sua utilização. 0 banco de dados selecionado foi de revistas científicas em turismo de expressivo fator de impacto, sobretudo no que concerne aos periódicos internacionais. O critério adotado foram as revistas brasileiras e internacionais classificadas pela Coordenação de Aperfeiçoamento de Pessoal de Nível Superior (Capes - Brasil) no escopo de A1 até B1, no estrato de Administração, Ciências Contábeis e Turismo, sendo selecionado alguma destas, conforme é destacado no quadro 01.

Quadro 01. Periódicos utilizados na pesquisa classificada pela Capes no escopo de A1 até B1.

Periódicos nacionais Periódicos internacionais

Cuadernos de Turismo,

Annals of Tourism Research,

Caderno Virtual de Turismo, Tourism Management,

Revista Brasileira de Pesquisa em Turismo, E-review of Tourism Research,

Turismo: Visão e Ação, Journal of Hospitality and Tourism Management, Journal of Human Resources in Hospitality \& Tourism, Tourism and Hospitality Research

Fonte: elaboração própria a partir da classificação da Capes, 2018.

Com os periódicos definidos, deu-se continuidade as fases indicadas no ProKnow-C, no que tange a exclusão de artigos repetidos, identificação do alinhamento dos artigos pelo título e resumo, e por fim, a leitura integral dos textos que estavam alinhados com a pesquisa. 0 portfólio bibliográfico encontra-se ilustrado no quadro 02, separado por tema.

Quadro 02: Portfólio bibliográfico básico da pesquisa

\begin{tabular}{|c|c|}
\hline Eixos temáticos & Artigos \\
\hline Abordagem conceitual de governança & $\begin{array}{l}\text { Velasco Gonzalez (2010); Tretin (2016); Hall (2011); Erkus-Ozturk \& } \\
\text { Eraydin (2010); Wan \& Bramwell (2015); Valente, Dredge \& Lohmann } \\
\text { (2015). }\end{array}$ \\
\hline $\begin{array}{l}\text { Governança e a relação com Estado e políti- } \\
\text { cas públicas }\end{array}$ & $\begin{array}{l}\text { Tang (2017); Andrades \& Dinamache (2017); Doods \& Butler (2010); } \\
\text { Baum (1994); Estol \& Font (2016); Garcia (2014); Almeida García, } \\
\text { Balbuena Vázquez, \& Cortés Macías (2015) }\end{array}$ \\
\hline Governança e redes de atores & $\begin{array}{l}\text { Bramwell \& Sharmam (1999); Qian et al.(2016); Urano, Siqueira \& Nó- } \\
\text { brega (2016); Tineo \& Tomazzoni (2017); Velasco Gonzalez (2010); } \\
\text { Tretin (2016). }\end{array}$ \\
\hline
\end{tabular}

Fonte: elaboração própria, 2018.

Este portfólio serviu de base para a construção e discussão da pesquisa. Os temas foram divididos conforme foram sendo elucidados a partir da leitura dos artigos. Percebe-se, assim, uma predominância de artigos internacionais em relação ao volume de artigos nacionais que abordam a temática.

É válido considerar que também foi realizada uma pesquisa bibliográfica baseada em livros de autores clássicos que abordam a temática. Assim, os dados foram analisados considerando a análise de conteúdo do tipo temática, considerando os três grandes temas sinalizados no quadro 02.

\section{ATUAÇÃO DO ESTADO NO DIRECIONAMENTO DO TURISMO: DESAFIOS INSTITUCIONAIS}

Ao longo dos séculos, mudanças sociais forçaram o Estado a assumir diversas posturas, no intuito de responder a um ambiente que têm diversos interesses e poderes de pressões diferenciados. Assim, surge o 
Estado moderno, o Estado absolutista, o Estado socialista, o Estado capitalista e o Estado liberal, como exemplos de regimes adotados para garantir um maior controle e legitimidade, tanto pelos meios de produção, quanto pelo meio social.

O principal propósito do Estado é garantir a ordem e defender o interesse público, enquanto esfera coletiva, isto é, na busca da sociedade igualitária e embora seja regulada e provida pelo Estado, a "coisa" pública envolve a preferência e vontades de todos os sujeitos da sociedade por meio das relações, ou seja, a busca pela sociedade dos iguais (Bresser-Pereira, 1995; Dias \& Matos, 2012).

Ocorre que a coisa pública é instrumento de ação do Estado que tem no governo o gestor destes recursos que tem a responsabilidade de garantir a ordem e segurança providas pelo Estado (Dias \& Matos, 2012). Neste caso, a administração dos negócios do Estado é realizada pelos governos que tem características de renovação em determinado período, mas que deve atuar em nome do Estado.

Dias \& Matos (2012) defendem que justamente pelo fato dos governos terem um prazo determinado e carregarem interesses particulares, de características próprias, o Estado fará com que estes interesses sejam atendidos durante o tempo em que permanecerem na administração, e afirmam que tal comportamento possibilita a constituição do personalismo dos governos, que é uma das características apontada na literatura que compõe o desafio da governança turística (Araújo et al., 2016; Dias \& Matos, 2012). Essa forma de governar está pautada no individualismo e no baixo fator de cooperação, onde as pessoas valem mais que as instituições enquanto coletivo.

Nóbrega (2012) destaca que a constituição de arenas públicas de turismo que procuram discutir democraticamente as melhores decisões no campo do planejamento e gestão estão atreladas a um processo de agregação de preferências individuais incutidas pelos representantes legais, e não, incorporam uma dimensão deliberativa stricto sensu, que envolve também a formação e a transformação das preferências na construção do consenso e na discussão do dissenso. Além disso, acredita-se que as instâncias de governança são demasiadamente desestimuladas ao exercício da participação no processo de planejamento e gestão devido à sobreposição de ações desencadeadas pelo resultado de inúmeras tentativas fracassadas de políticas voltadas ao turismo desde a década de 1970. 0 autor ainda destaca que as instâncias de governança turística tomaram uma forma organizacional que atende às preferências individuais pautadas no aspecto unicamente econômico, como por exemplo, o Programa de Regionalização do Turismo (PRT), pautado na construção de produtos materializados a partir da construção de roteiros turísticos, ou seja, um viés comercial, portanto, não havendo a intenção de promover o desenvolvimento em uma perspectiva local/regional defendido pelo programa, pois as ações não contemplam os preceitos do desenvolvimento endógeno, baseado na busca do bem-estar econômico, social e cultural da comunidade local em seu conjunto através de uma participação ativa da sociedade, mas sim, atende aos interesses quase que exclusivos da reprodução do capital financeiro internacional.

O estudo de Araújo et al. (2016), também corrobora nesta perspectiva quando revela, por exemplo, que a dificuldade de operacionalização da governança turística está diretamente relacionada com a dificuldade que o país enfrenta quando o assunto trata-se de dar continuidade às ações políticas, já que em muitos casos, novos gestores assumem o cargo e não continuam a executar atividades anteriores.

Coutinho (2015), por sua vez, aponta que como o personalismo político gera um foco voltado somente para os interesses da administração, especificamente, do gestor que está a frente, isto também contribui para a descontinuidade das ações e forte dependência política. O inverso disto estaria em nome da busca da coletividade das ações e do bem comum, independente de gestor e cargo político

Há muitos riscos com esse modelo, uma vez que a sociedade cria uma expectativa à espera de novas gestões governamentais com características inovadoras, na tentativa de solucionar os problemas e quando ocorre, rapidamente poderá sofrer com a descontinuidade das ações, e assim adquire uma conotação personalista do novo governo. Assim, o personalismo é um empecilho para a construção de uma gestão democrática e participativa que é uma das características da governança turística. Atua-se em nome de poucos, visando interesses particulares.

O Estado, desta forma, assume diversos papéis em cenários diferenciados, considerando as diversas pressões que sofre. Dias \& Matos (2012) defendem que o papel do Estado deve ser de quatro tipos: 
regulador, facilitador, aliado e apoiador nas decisões públicas e afirmam que "os quatro papéis não necessariamente devem ser desempenhados separadamente, nem mesmo excluem-se os mecanismos de um em relação ao outro" (p. 193), devem ser pensados como uma mescla de fatores para atender os diversos interesses existentes no jogo político.

Por sua vez, Velasco González (2013) e Tretin (2016),em uma visão mais objetiva, ressaltam a necessidade de um papel de coordenador frente aos objetivos conflitantes que assume no mundo contemporâneo. A OCDE (2013) também reforça a necessidade de uma postura coordenadora como forma de melhorar os resultados das ações públicas e que possa gerar resultados positivos na constituição da governança turística.

É importante considerar, que nos últimos anos, foi promulgada uma nova forma de se fazer política no mundo e consequentemente no Brasil, baseada em ideais descentralizadores, mas que não foi acompanhada de capacidade institucional de cada governo municipal. 0 foco passa a ser a disputa de elites locais (Arretche, 1998), emergindo uma descentralização com diversos governos centralizados, por meio da regulação que é o segundo desafio da governança turística.

Tal característica - reguladora - está ancorada no percurso histórico do Estado, que tinha como papel o controle por meio de processos centralizados, na busca do bem comum da sociedade. A postura como regulador respondia as necessidades do seu contexto, mas que não atende a contemporaneidade que busca por espaços participativos.

Macêdo et al. (2016) afirma que o papel do Estado no direcionamento do turismo é um elemento fundamental, apesar de suas limitações e dificuldades, especialmente no contexto democrático de descentralização das ações junto com os demais atores envolvidos. Seki (2013) aponta em sua pesquisa realizada no Japão que a postura de coordenador do Estado, dentro de uma área que tem diversos interesses, não é uma tarefa fácil, mas garante a efetividade e sustentabilidade dos destinos turísticos no contexto de democracia social. Por isso, defende-se que o Estado deve deixar de ser regulador e assuma uma postura coordenadora das ações públicas, evitando uma dependência e supere, de fato, o paradigma hierárquico a favor de um cenário do bem comum.

A atuação, no estabelecimento de ações mais coordenativas, poderá ocorrer de forma prática por meio de políticas públicas como um instrumento de ação estatal (Schenkel \& Almeida, 2015). A definição de políticas públicas, neste sentido, é um dos termos amplamente debatidos na literatura e cada autor carrega consigo uma visão e percepção, gerando uma "indefinição" universalmente aceita. No entanto, a maioria de suas definições retrata o processo de tomada de decisão por parte dos governos que conforme avança no percurso histórico, verifica-se que há a inserção, não somente do governo, mas ele como um dos atores no processo de decisão de política pública (Goeldner \& Brent, 2011; Cruz, 2000; Velasco Gonzalez, 2013).

Se não há um consenso na sua definição, é importante esclarecer o que não é política pública de turismo. De acordo com Velasco Gonzalez (2013) a política de turismo: a) não é qualquer ação pública que trate sobre o turismo, b) não é qualquer aprovação de norma para o setor e também c) não é simplesmente uma intenção política de trabalhar com o tema de turismo. Desse modo, entende-se a política pública de turismo como um conjunto de ações dos atores públicos que, em colaboração com outros setores, tem a intenção de alcançar objetivos diversos relacionados com a variedade do fenômeno turístico. Aqui, busca-se resgatar a ação coerente do turismo, com suas problemáticas definidas e o papel dos atores públicos que atua em âmbito territorial onde devem dialogar com seus pares. Deixa-se de lado a intenção do turismo e/ou qualquer ação, e passam a observar a tônica dos problemas do fenômeno turístico, inclusive, antevendo-as com todas as suas relações.

As razões para promover o turismo em determinada localidade deverá estar explícita nas políticas públicas. Este também é o motivo pelo qual algumas políticas funcionam em determinada localidade e em outra não, isto é o enfoque/ação do Estado no direcionamento das ações do turismo. No entanto, o impacto econômico tem sido o motivo mais relevante para incentivar e/ou desenvolver ações (Tang, 2017; Garcia \& Chahine, 2016; Estol \& Font, 2016), não só na percepção da gestão pública, mas também dos residentes (Garcia et al., 2015) que conseguem enxergar uma gama de fatores positivos e negativos em relação ao fenômeno turístico. 
Apesar de preconizar melhorias econômicas e observar muitos discursos neste sentido, há uma baixa efetividade de políticas que realmente destaque o turismo como meio de geração de renda e mudanças sociais. No continente europeu, Doods \& Butler (2010) apontam que as políticas da Espanha focam a prioridade econômica acima das questões ambientais, e que este tipo imediatista está relacionado a ações de curto prazo pautado no personalismo e descontinuidade dos governos. Na EuroÁsia, Andrades \& Dinamanche (2017) discutem o modelo de governança na Rússia, que apesar do país ter grande potencialidade, não considera o turismo como prioridade e tem muitos desafios para se tornar um destino competitivo. Na América do Sul, Araújo et al. (2016) demonstram em estudos realizados no nordeste Brasileiro, que apesar de existir investimento financeiro no turismo, as ações não tem sua devida relevância, causando diversos transtornos como a diminuição do turismo na localidade e impactos, principalmente,à comunidade local. 0 que os estudos demonstram em comum é que a inclusão do turismo na agenda pública como elemento prioritário ainda é uma realidade distante, denotando grande fragilidade do turismo no processo de desenvolvimento local e a preconização das melhorias econômicas do turismo. As políticas permanecem no campo do discurso sem efeitos práticos.

Por outro lado, há cenários positivos quando se investe no turismo revelando que é recompensador dedicarse à atividade turística. Os estudos de Schenkel \& Almeida (2015) contribuem nesta perspectiva,por exemplo, na Argentina, onde se observou investimento estatal com ações prioritárias no turismo para reerguer o país de uma crise econômica que ocorreu em 2001. Moldaram-se as relações sociais e econômicas e a presença do Estado não foi dominadora ou teve atuação mínima, apenas de coordenador e investidor nas ações do turismo.

Investir em infraestrutura básica não significa exatamente o investimento em política turística e/ou que seja uma política pública de turismo, conforme evidenciado por Velasco Gonzalez (2013). Há uma escassez de recursos destinada ao turismo e não há uma objetividade nas ações. Percebe-se, assim, que a relevância é diminuída no cenário diante da magnitude de sua prática e discursos políticos, sociais e empresariais, corroborando ao terceiro desafio da governança turística.

Entende-se que o Estado é o elemento condutor das ações e iniciativas do turismo, podendo influenciar de forma direta nas decisões, por meio de políticas públicas, ou de forma indireta, em ações transversais, ou ainda, por meio de organizações no novo contexto social. Com isso, a atuação do Estado e o direcionamento das políticas públicas contemporâneas são movidos por uma questão complexa, interdependente e dinâmica, correlacionando com diversos setores para o seu êxito. Não se deve somente analisar as políticas públicas, mas toda sua conjuntura que delimitará o direcionamento do Estado nas ações de desenvolvimento do turismo.

Nesse contexto, Velasco Gonzalez \& Tretin (2014) afirmam que as diversas dimensões das políticas públicas podem ser analisadas por meio dos seus instrumentos, que são de dois tipos: (1) os instrumentos substantivos que englobam as estruturas administrativas tradicionais (Administrações Nacionais de Turismo - NTA, a exemplo do Ministério do Turismo) e as estruturas administrativas executivas (Organismos Nacionais de Turismo - NTO, a exemplo dos Escritórios Nacional de Turismo, que o governo faz uso para cumprimento de seus fins); e (2) os instrumentos procedimentais que pressupõem um suposto enfoque de redes com características de certa autonomia organizativa, como é o caso dos espaços de cooperação pública e privada, e também das instâncias de governança. Os instrumentos procedimentais dão um novo tom à dinâmica e operacionalização do turismo nas localidades. Este grupo é mais difuso, englobando certa autonomia organizativa, que a partir de iniciativas de cooperação voluntária ou involuntária, contribui para a gestão do turismo nas destinações turísticas.

Desse modo, os instrumentos organizativos são integrados pelas instituições públicas, executivas e de cooperação (figura 01). A implementação de políticas públicas requer o envolvimento de ações mais coletivas, e os instrumentos procedimentais corrobora este novo contexto para o pleno êxito das políticas. 
Figura 02: Instrumentos organizativos da política pública de turismo

\begin{tabular}{|l} 
Figura 02: Instrumentos organizativos da política pública de turismo \\
INSTITUCIONES \\
INSTITUUCIONES \\
EJECUTIVAS
\end{tabular}

Fonte: Velasco Gonzalez e Tretin, 2014.

Estes instrumentos podem ser analisados de forma sequenciada - como comumente é realizado no caso latino americano, ou de forma aleatória - como ocorre nos países desenvolvidos, onde muitas vezes não há necessariamente uma política pública definida, mas há execuções de política, uma vez que a sua existência não implica necessariamente em sua execução (Baum, 1994).

Esta nova forma de se fazer política, está ancorada no processo de crescente monopólio industrial e financeiro, que alterou o modo de acumulação capitalista, abrindo os mercados ao cenário externo, que ocasionou uma reorganização nas funções do poder administrativo local. Em contrapartida, também ocorreu um processo crescente de pressão e demanda social por parte da sociedade gerando opinião e expectativa. Não é de se estranhar, portanto, que essa situação contraditória com os grandes interesses econômicos necessite de uma mudança por parte da administração, abrindo mais espaços para diálogo e participação (Alió \& Jori, 2011).

A participação social, neste processo, é condição sine qua non no processo de democracia representativa contemporânea. Nesse sentido, Tineo \& Tomazzoni (2017) defendem a necessidade de compartilhamento de poder do Estado com a sociedade no contexto da democracia para o bom êxito da governança turística. Baum (1994) e Qian et al. (2016) entendem que é a comunidade que detém o conhecimento prático,e por isto que o fator humano é consistente no processo de desenvolvimento de políticas, mas que há a postura de um ditador nas decisões públicas e por isto, são visto como periféricos neste processo. Não se permite que ocorra a participação na sua ampla concepção, com mecanismos e regras claras de participação.

A falta de autonomia e forte centralização da administração pública são grandes entraves ao processo de governança. Entende-se que é a partir de oportunidades que são ofertadas a comunidade local, que se pode chegar ao desenvolvimento do turismo. A postura do ditador, revelado pelos estudos, corroboram ao quarto desafio institucional da governança turística nos destinos turísticos.

Percebe-se, assim, que a mudança estatal no mundo globalizado tem suas origens ainda arraigada no seu percurso histórico que carregam consigo um modo conservador que desafiam a consolidação da governança turística. Foi evidenciado, através das discussões teóricas, que há um modelo tradicional que é conflitante com o que a teoria preconiza como sendo benéfico para o contexto das novas estruturas de gestão que são desenhadas na figura 03. 
Figura 03. Desafios institucionais para a governança turística

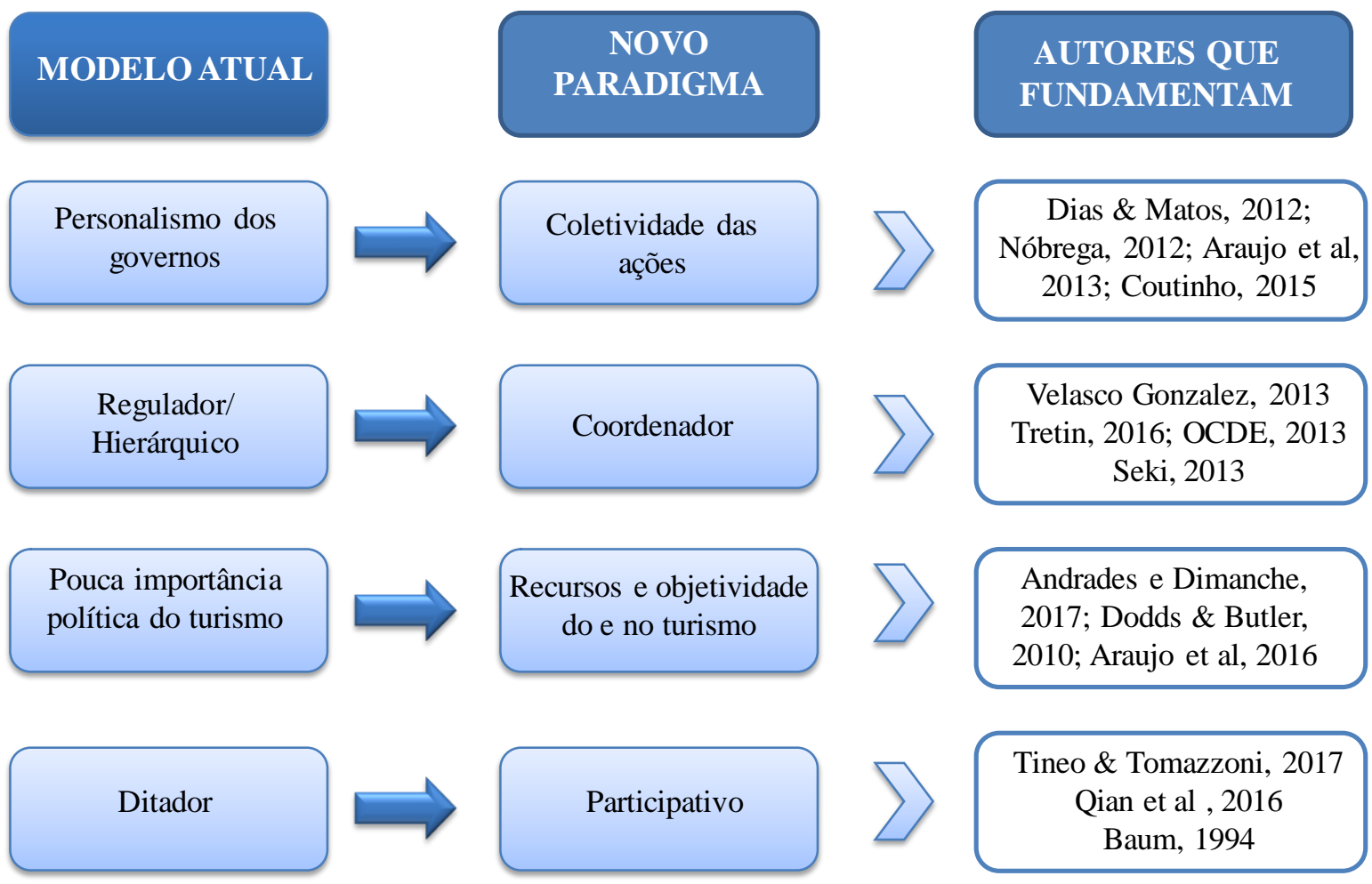

Fonte: elaboração própria, 2018.

Assim, à luz da figura 03 identifica-se que há uma forte característica personalista dos governos que predomina, ainda, na sociedade pós-moderna que anseia por ações mais democráticas e coletivas. Com base nisto, autores (Velasco Gonzalez, 2013; Tretin, 2016; OCDE, 2013; Seki, 2013) defendem uma postura mais coordenadora do Estado no direcionamento das ações, sendo confirmada por diversos estudos (Macêdo et al., 2016; Seki, 2013) que demonstram resultados mais eficaz e eficiente nas localidades a partir desta ação, entretanto, predomina uma postura reguladora e hierárquica estatal que está diretamente relacionado ao seu percurso histórico. Esta postura reguladora, por sua vez, não beneficia a inclusão do turismo na agenda pública como um elemento prioritário, o que faz com que a atividade como elemento de desenvolvimento das localidades e dinamização das economias permaneça nos discursos através das ações de política pública e com pouco efeito prático com diretrizes mais efetivas que venha a contribuir com o processo de desenvolvimento do turismo no contexto mais amplo. Ademais, há um processo de mudança social que luta por espaços mais participativos (Tineo \& Tomazzoni, 2017; Baum, 1994; Qian et al, 2016) dentro de um contexto democrático que confronta diretamente com a postura ditatorial estatal.

Neste sentido, há uma busca de um novo paradigma de atuação do estado no direcionamento do turismo em busca de ações mais coletivas e participativas, por meio de uma postura estatal coordenadora, gerindo recursos e proferindo objetividade nas ações do turismo que provoquem a real promoção de desenvolvimento local dos destinos turísticos. É a partir desta concepção de uma nova leitura do Estado, que esse trabalho dá ênfase. Assim, na seção 4 será discutido os elementos da governança enfocando nas redes de atores e seus desafios organizacionais.

\section{GOVERNANÇA TURÍSTICA NOS DESTINOS TURÍSTICOS E O ENFOQUE NAS REDES: DESAFIOS ORGANI- ZACIONAIS}

A literatura destaca que o termo governança em turismo está associado à forma de governar, que implica um redimensionamento no comando e controle por parte do Estado, que passa a inserir novos atores no processo de decisão, através de novas estruturas, mecanismos e procedimentos de tomada de decisão do planejamento e operação do fenômeno turístico. 
De acordo com Hall (2011) a governança está associada ao ato de governar "buscando entender como o Estado pode agir de forma a mediar o desenvolvimento social, econômico, social e problemas de política em uma época em que o próprio papel do Estado mudou". Esta mudança passa a inserir novos atores no processo de desenvolvimento que ultrapassa as questões de governo.

A governança, na perspectiva de Wan \& Bramwell (2015) adquire o envolvimento de atores governamentais e não governamentais que trabalham juntos coletivamente, para assegurar uma meta coletiva ou ordem social. Atribuindo ao Estado o papel de coordenador frente aos novos desafios.

Por sua vez, Valente, Dredge \& Lohmann (2015) define como o processo que garante maior transparência, prestação de contas, eficácia, eficiência, participação e legitimidade que podem ser alcançadas em parcerias público-privadas.

Em todas as definições, há uma predisposição de entender a governança como um processo inerente ao governo ou como forma de governar. No entanto, Velasco Gonzalez (2013) propõe entender a governança como um procedimento organizativo de tomada de decisão, que inclui não somente as ações do governo. Para a autora, governança é uma "nova forma de liderar os processos de inovação, fortalecimento e mudanças das dinâmicas turísticas em um espaço determinado, incorporando os atores públicos e privados com a intenção de tomar decisões coletivas". Com isso, a governança pode ser vista como um processo e não um fim em si, que inclui a mudança do Estado através da incorporação de diversos atores no processo de tomada de decisão.

No Brasil, a abordagem em governança turística teve como base a estruturação e organização do turismo baseada na região, por meio de agrupamentos municipais reforçando a criação da articulação em redes. Desse modo, as instituições passam a se organizar pelas redes interorganizacionais, como condição e resultado de uma racionalidade de uma nova dinâmica social, cultural e política de uma determinada região.

Cabe-se questionar quem são estes atores que ultrapassa a gestão pública no processo de governança?Eles são divididos em três principais tipos: atores do setor privado, atores do setor público e a sociedade civil que passou a ser denominada como terceiro setor.

- Os atores privados: São dotados de capacidade financeira e no turismo faz-se referência ao empresariado que incentivam o crescimento da atividade por meio de seus investimentos privados e por isto, há um direcionamento de planos e programas de apoio ao desenvolvimento do setor com foco nestes atores. Tem forte característica econômica e competitiva, uma vez que busca o lucro em curto espaço de tempo. De acordo com Velasco Gonzalez (2013) tem alto grau de autonomia e flexibilidade (Seki, 2013; Coutinho, 2015; Velasco Gonzalez, 2013).

- Atores públicos: São as estruturas administrativas responsáveis pela criação de órgãos de decisão e participação, ou qualquer outro tipo que incidam na capacidade organizativa. São dotados de poder político e cuja função básica é a prestação de bens e serviços, a captação e gestão de recursos, acumulação de informações e assessoramento. Suas ações estão fortemente ligadas com seu entorno e ao longo do primeiro tópico foram discutidas suas principais características e as diversas pressões que sofreu ao longo do tempo e como isto interfere na governança turística (Dias \& Matos, 2012; Andrades \& Dinamache, 2017; Velasco Gonzalez, 2010).

- Comunidade/terceiro setor: existe um grupo de atores que é bem mais difuso que os anteriores e denomina-se terceiro setor. Surgiu na Europa como um sistema de representação da sociedade, já no Brasil, nasce atrelada a projetos de cooperação internacional, como instituição progressista para consolidar a democracia e por isto esta associada a um poder intelectual quer por sua capacidade de organização ou pelos resultados dessa formação. Sua estruturação no turismo é organizada por meio de vários tipos: associações, câmaras, conventions bureau, universidades, etc. e busca através da sua representação legitimar o processo decisório (Qian et al., 2016; Baum, 1994).

Têm-se, dessa forma, três tipos de atores com poderes diferenciados que são representados dentro do contexto da governança que devem conjuntamente decidir sobre o bem comum e direcionamentos da atividade turística. Entende-se que a governança turística é um paradigma político, caracterizada pela 
interrelação entre diversos atores e redes de relacionamentos criadas entre eles, implicando em uma acumulação de capital social (Tineo \& Tomazzoni, 2017).

Deste modo, o conceito de redes para estudar governança permite reconhecer a multiplicidade dos atores locais que são dependentes de ações conjuntas. A cooperação destes atores ajuda a reduzir as dúvidas, aumentando a eficiência nas ações políticas e enfrentar as pressões externas. Baseia-se em critérios de confiança e reciprocidade elevando a uma lógica da cooperação para atingir um objetivo comum (Putnam, 2006; Coutinho, 2015; Rovere, 1999).

A abordagem da política em redes possibilita a equidade de participação e distribuição dos benefícios a todos os envolvidos. É consenso, na literatura, (Urano, Siqueira \& Nóbrega, 2016; Velasco Gonzalez, 2010; Tretin, 2016; Coutinho, 2015; Fleury, 2002) que a cooperação é a melhor forma de se obter êxito numa determinada política pública, evitando a visão separatista das abordagens entre política e administração, usualmente realizadas por pesquisadores da administração tradicional. Os estudos apontam que, além de ser uma nova perspectiva de análise, também representa uma nova forma de organização social face aos problemas políticos de (des)coordenação e de (des)mediação social.

Desse modo, as redes sociais caracterizam-se por atores independentes, que mantêm relações, logo, requer o desenvolvimento de habilidades e competências especiais de cada sujeito. Seguindo este pressuposto, todos os atores teriam o mesmo objetivo e sinergia e possuem através da potencialidade deste agrupamento almejar o fortalecimento da região turística. Além disso, precisa contar com um entorno favorável, para que essas redes se estabeleçam e possibilitem o desenvolvimento local.

O envolvimento de um ator, em uma rede, se dá pela necessidade de compartilhar recursos (e não apenas financeiros) para atingir um objetivo comum, isto é, cada ator representado tem um objetivo particular, embora o pleno êxito esteja vinculado a uma construção de um objetivo maior que tem um valor compartilhado. Permanecem os objetivos e vontades particulares, mas só são alcançados a partir de uma visão global, através da cooperação. No entanto, observa-se nos estudos (Baum, 1994; Seki, 2013; Qian et al., 2016) que há uma tendência em defender os interesses pessoais, sobrepondo aos demais, onde os setores que tem maior poder de representação adquirem maior conotação, deixando de lado os ideais cooperativos que são defendidos na governança baseada na redes de atores.

É válido destacar o caráter antagônico das redes sociais caracterizado por um lado de integração, diálogo e aproximação, e de outro, a competição, individualismo e intolerância, beneficiando os grandes grupos econômicos. Assim, quanto maior for o nível de interação da rede, menor tenderão a ser suas divergências. 0 estudo de Qian et al.(2016) realizado na China, demonstrou que existe uma atitude defensiva ao invés de cooperação na governança dos destinos turísticos, mas os autores também apontam que não é somente as relações que determinam a posição de cada ator dentro da rede, mas, em especial, a análise da rede em sua conjuntura, considerando, inclusive, os aspectos externos a rede.

Destarte, Rovere (1999) estabelece um esquema para identificar vínculos de uma rede. Cada nível identificado pelo autor serve de apoio ao que segue: reconhecimento da existência do outro, conhecimento, colaboração, cooperação e associação, que é seu último nível. Esses vínculos estão associados não, apenas aos níveis, mas também às ações e aos valores que estão envolvidos e cada vez que partilham dentro da rede, maior será o vínculo dentro dela.

Por sua vez, Tretin (2016), propõe entender as redes de governança em turismo em três aspectos crescentes: a coordenação, a colaboração e a cooperação. Onde a coordenação se refere à ação do setor público estatal no direcionamento das ações de desenvolvimento do turismo. A colaboração é o processo de interação dos diversos atores com a finalidade de construir regras e normativas e; a cooperação como um resultado comportamental dessas relações inteorganizacionais, que é imbuída de compartilhamento de informação de forma autônoma e com isso a autoridade passa a ser individual, sem poderes de pressão dentro do grupo.

É notório que as redes são geridas por um processo autônomo, voluntário e altamente dinâmico, requerendo de todos os atores/agentes o sentimento de pertencimento e cooperação. Os integrantes, assim, devem estar abertos e propícios a novas interferências que venham a beneficiar a localidade, eliminando as barreiras do conhecimento e do estranho. 
Não há um consenso de uma matriz para efetivar ações (de cima para baixo ou de baixo para cima). Os processos começam de onde se pode ou deseja buscar a solução dos problemas, isto é, os atores da rede não podem esperar que o outro concretize as ações que foram pensadas em conjunto e que são de interesses de todos. Como uma rede, seus atores podem e devem se ordenar para concretizá-lo. Entretanto, a horizontalidade é o formato desejado já que devem se envolver e serem envolvidos no processo de participação.

Com isso, a gestão de redes de políticas requer processos de decisões que sejam contínuos e estáveis, mas existem algumas condicionantes nesse processo que foi evidenciado através dos resultados das pesquisas: esses atores agem em função de suas percepções em relação aos demais atores e às expectativas de seus comportamentos (Tretin, 2016; Velasco Gonzalez, 2013; Tineo \& Tomazzoni, 2017; Fleury, 2002). Com base nisso, cada ator definirá sua estratégia de ação:a) a capacidade de mobilização de recursos dos atores dependerá tanto dos recursos que cada um controla quanto da sua representação fora da rede - que está diretamente relacionado ao entendimento do papel de cada um dentro da rede; b) consenso nas decisões para que possa chegar a um entendimento comum - indo ao encontro dos diversos poderes que são representados dentro da rede, onde um setor pode ter maior controle e poder dentro da rede; e c) nível de interesse de resolver as questões realmente relevantes - relacionada ao envolvimento de cada um na rede de governança, através do empoderamento (Bramwell \& Sharmam, 1999; Hall, 2011; Urano, Siqueira \& Nóbrega, 2016; Coutinho, 2015).

Diante do exposto, identificou-se que os desafios organizacionais estão relacionados com a forma que a rede de governança está imbricada, sendo três os principais desafios demonstrados na figura 04.

Figura 04. Desafios organizacionais na governança turística

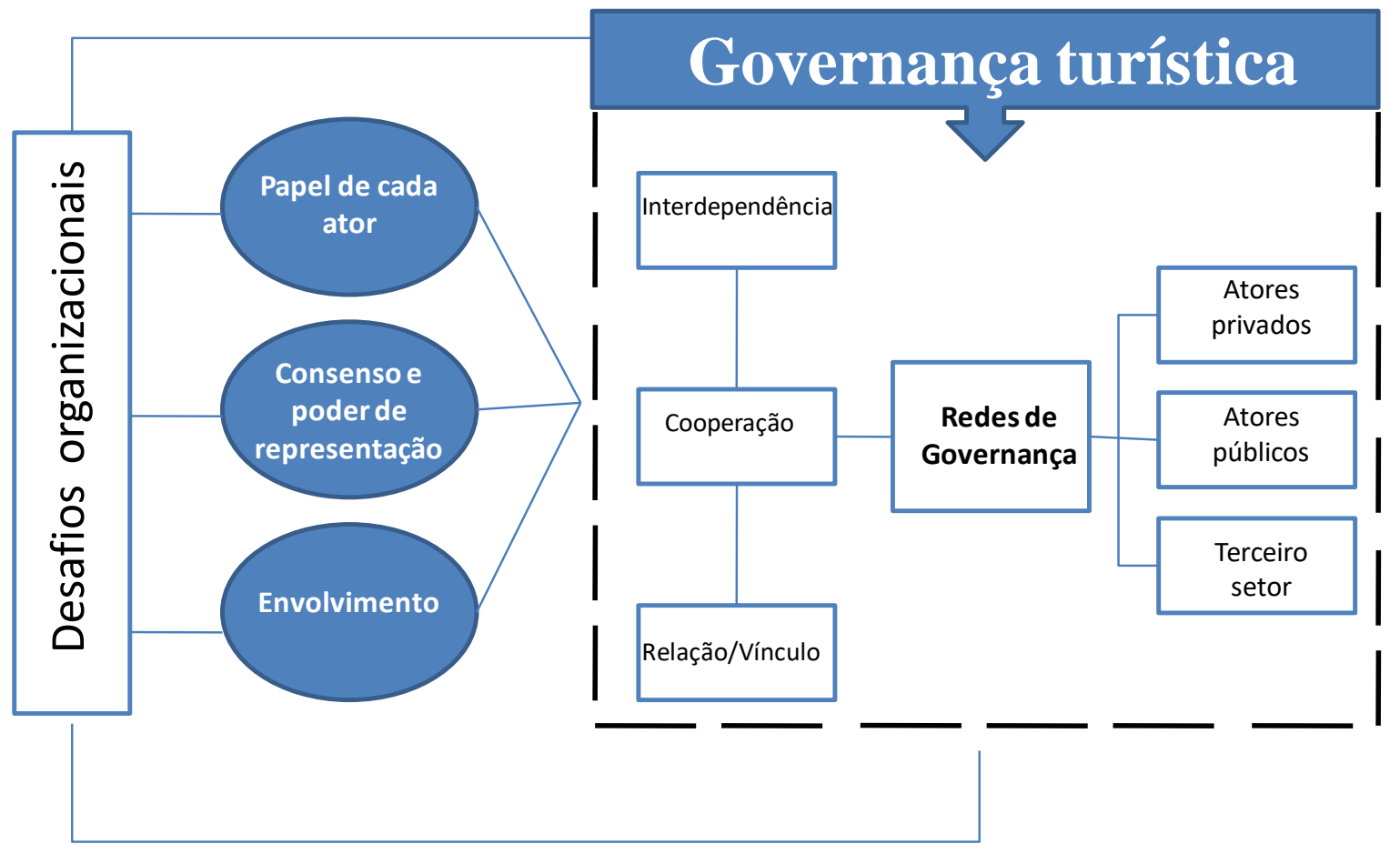

Fonte: Elaboração própria, 2018.

A luz da figura 04 destaca-se que as redes de governança são compostas por três tipos de atores identificados na literatura: atores privados, públicos e do terceiro setor, tendo como condição de existência um vínculo que justifique a sua união que congrega ações individuais, mas que são atingidas por meio do seu coletivo, e, por isto, estão imbricados em uma relação de interdependência como condição de existência e de cooperação para o sucesso de suas ações. Este é o cerne das estruturas de governança organizativas em turismo. No entanto, através da discussão da literatura foram apontados três tipos de desafios 
organizacionais na governança turística: o envolvimento de cada ator dentro da rede, definida por meio do seu empoderamento e nível de interesse da problemática definida; o entendimento do papel de cada ator dentro da rede como sendo um dos grandes desafios, uma vez que as estruturas de governança, principalmente, no contexto brasileiro, foram criadas como estruturas administrativas impositivas, carecendo de uma discussão sobre a sua importância e os principais frutos que podem ser gerados a partir daquela relação e correlação; e por fim, o consenso e poder de representação de cada um dentro da rede para o entendimento comum, evitando sobreposição de poderes e interesses pessoais dentro da rede.

Com isso, identifica-se que os principais desafios organizacionais estão diretamente relacionado ao novo contexto das redes interorganizacionais e para isto, requer estruturas que propiciem o seu desenvolvimento a partir da relação e cooperação de diversos atores que estejam em sintonia com este processo.

\section{CONSIDERAÇÕES FINAIS}

O fenômeno turístico pode ser entendido como uma complexa rede de relação na qual faz parte diversos atores locais e por isto, impõe uma lógica própria que é a da cooperação. Para o desenvolvimento da governança turística nas destinações, faz-se necessária a participação e articulação entre os diversos entes neste processo. A maneira pela qual esses atores interagem, poderá influenciar na forma como a atividade se desenvolverá nas localidades, principalmente no novo contexto social e estatal que desenham cenários mais democráticos e participativos

Dentro desta complexa relação, este trabalho discutiu-se os principais desafios para a constituição da governança nos destinos turísticos, por meio da metodologia ProKnow-C, que mapeou textos que permitiram basear reflexões dos principais resultados no Brasil e no mundo acerca do tema.

Então, a partir da seleção dos textos, categorização e discussão, identificaram-se dois tipos de desafios: os institucionais, associada às questões do Estado, suas características e pressões que sofreu ao longo dos anos que desafiam a constituição da governança, sendo elas: o papel regulador/hierárquico do Estado, o personalismo dos governos, a postura ditadorial e a baixa importância atribuída ao turismo; e as organizacionais, que se refere à relação entre os atores participantes da governança que tem no seu cerne a existência de interdependência, cooperação e uma relação que justifique o seu vínculo,sendo elas: o entendimento do papel de cada um dentro da rede que o faça agir conforme a sua representação e resolutividade dos conflitos, os diversos poderes constituintes desta arena, que em muitos casos,são sobrepostos em função de outra representação, adquirindo maior representatividade neste contexto, e o nível de envolvimento e cooperação entre os atores no processo de empoderamento visando em uma escala menor os objetivos particulares, mas que são atingidos por meio de um entendimento do bem comum.

Identifica-se, assim, que os desafios identificados através da mineração e sua discussão são semelhantes tanto na literatura tanto quanto na internacional. No entanto, não significa afirmar que a solução seja semelhante para os destinos turísticos. Deve-se abandonar a ideia do modelo ideal de governança, e buscar olhar para as lacunas internas de cada processo, diante do seu contexto e suas relações. As dificuldades são conjunturais e não estruturais e por isto, que este trabalho discute o contexto conjuntural que dificulta o processo de constituição da governança turística.

Vale ressaltar, contudo, que não se esgotam neste trabalho as discussões acerca dos desafios da governança turística, tendo em vista que se busca elucidar os principais resultados identificados na literatura, mas há contextos específicos, tendo em vista o papel de cada nó que compõe a rede, os processos que conectam e o contexto em que foram criadas. Além disso, novas reflexões e questionamentos podem surgir a partir das ponderações que foram aqui apresentadas, na intenção, por exemplo, de elucidar as dimensões da governança turística visando à discussão para além das fragilidades no processo de planejamento e gestão dos destinos turísticos, mas principalmente na sustentabilidade dos destinos.

Constitui, ainda, como limitação de estudo o universo de textos minerados para a discussão dos dados. Escolheu-se uma única base de dados: revistas científicas de alto impacto, mas sabe-se que novas discussões e descobertas podem ser realizadas a partir da ampliação da base de dados em outras fontes. 


\section{REFERÊNCIAS}

Alió, M. \& Jori, G. (2011). Les societats urbanes davant la reforma ambiental: vision I propostes al voltante de la sostenibilitat. Barcelona: grups de Geógrafs per a L’Ecologia Social. Universitat de Barcelona.

Almeida García, F., Balbuena Vázquez, A., \& Cortés Macías, R. (2015). Resident's attitudes towards the impacts of tourism. Tourism Management Perspectives, 13, 3340. https://doi.org/10.1016/j.tmp.2014.11.002

Andrades, L.\& Dinamache, F. (2017). Destination competitiveness and tourism development in Russia: Issues and Challenges. Tourism Management, 62, 360-376. https://doi.org/10.1016/j.tourman.2017.05.008

Araujo, M. et al. (2016). O turismo potiguar que chegou a perder 100 mil desembarques! Revista Brasileira de Pesquisa em Turismo. 10(3), 594-614. https://doi.org/10.7784/rbtur.v10i3.954

Arretche, M. (1998). Tendencias no Estudo sobre avaliação. In Rico, E. Avaliação de políticas sociais: uma questão em debate. São Paulo: Cortez.

Baum, T (1994). The development and implementation of national tourism policies. Tourism Management, 15 (3), 185-192. https://doi.org/10.1016/0261-5177(94)90103-1

Beaumont, N. \& Dredge, D. (2010). Local tourism governance: a comparison of three network approaches. Journal of Sustainable Tourism, 18(1), 7-28.

Bramwell, B. \& Sharman, A. (1999). Collaboration in loca tourism policymaking. Annals of tourism Research, 26 (2), 392-415. https://doi.org/10.1016/S0160-7383(98)00105-4

Bresser-Pereira, L. C. (2000). A reforma gerencial do Estado de 1995. Revista de Administração Pública, 34(4), 55-72. https://doi.org/10.9.2000

Caffyn, A. \& Jobbins, G. (2003). Governance capacity and stakeholder interactions in the development and management of coastal tourism: Examples from Morocco and Tunisia. Journal of sustainable Tourism, 11(2), 224-245. https://doi.org/10.1080/09669580308667204

Castells, M. (2000). A sociedade em Rede. São Paulo: Paz e Terra.

CAPES - Coordenação de Aperfeiçoamento de Pessoal de Nível Superior. (2016). Plataforma Sucupira. Retrieved November 12, 2018, from https://sucupira.capes.gov.br/sucupira/public/consultas/coleta/veiculoPublicacaoQualis/listaConsultaGeralPeriodicos.jsf

Coutinho, A. (2015). Políticas públicas, desenvolvimento local e participação social nas instâncias de governança associadas ao turismo no Rio Grande do Norte. Dissertação de Mestrado. Programa de Pós-Graduação em Turismo. Universidade Federal do Rio Grande do Norte, Natal, Brasil.

Cruz, R. (2000). Políticas de turismo e território. São Paulo: Contexto.

Dias, R. \& Matos, F. (2012). Política pública: princípios, propósitos e processos. São Paulo: Atlas.

Dodds, R. \& Butler, R. (2010) Barriers to implementing sustainable tourism policy in mass tourism destinations. Tourismos, 5 (1), 35-53.

Ensslin, L. et al. (2010). ProKnow-C, Knowledge Development Process-Constructivist. Processo técnico com patente de registro pendente junto ao INPI. Brasil: Instituto Nacional de Propriedade Industrial.

Erkus-Ozturk, H. \& Eraydin, A. (2010). Environmental governance for sustainable tourism development: Collaborativa networks and organisation building in the Antalya tourism region. Tourism Management, 31(1), 113-124. https://doi.org/10.1016/j.tourman.2009.01.002

Estol, J. \& Font, X. (2016). European tourism policy: Its evolution and structure. Tourism Management, 52, 230-241. https://doi.org/10.1016/i.tourman.2015.06.007

Fleury, S. (2002). O desafio da gestão das redes de políticas. VII Congress Internacional del CLAD sobre la Reforma del Estado y de la Administración Pública. Lisboa: Portugal.

Garcia, F. (2014). A comparative study of the evolution of tourism policy in Spain and Portugal. Tourism Management, 11, 34-50. https://doi.org/10.1016/j.tmp.2014.03.001

Garcia, F. et al. (2015). Resident's attitudes towards the impacts of tourism. Tourism Management Perspectives, 13, 33-40. https://doi.org/10.1016/j.tmp.2014.11.002 
Garcia, F. \& Chahine, S. (2016). Evolución de la política turística y la intervención estatal. El caso de Marruecos. Cuadernos de Turismo, 38, 13-37. https://doi.org/10.6018/turismo.38.271331

Goeldner, C. \& Brent, R. (2011). Tourism: principles, practices, philosophies. New Jersey: John Wiley Sons.

Hall, C. (2011). A typology of governance and its implications for tourism policy analysis. Journal of Sustainable Tourism, 19(4-5), 437-457. https://doi.org/10.1080/09669582.2011.570346

Nóbrega, W. R. M. (2012). Turismo e Políticas Públicas na Amazônia Brasileira: instâncias de governança e desenvolvimento nos municípios de Santarém e Belterra, Oeste do Estado do Pará. Tese de Doutorado. Programa de Pós-Graduação em Desenvolvimento Sustentável do Trópico Úmido. Universidade Federal do Pará.

Nóbrega, W. R. M. \& Figueiredo, S. J. L. (2014). Turismo e gestão pública: uma avaliação das instâncias de governança no Oeste do Estado do Pará. In: Pimentel, T. D.; Emmendoerfer, M. L. \& Tomazzoni, E. L. (Org.). Gestão Pública do Turismo no Brasil: Teorias, Metodologias e Aplicações. Caxias do Sul: EDUCS.

OCDE. (2013). Governança multinível para políticas de desenvolvimento regional mais eficazes. In: Relatório territorial da OCDE: Brasil. OECD Publishing. 161 - 231. https://10.1787/9789264189058-pt

Qian, C. et al. (2016). Effective governance in tourism development - An analysis of local perception in the Huangshan mountain área. Tourism Management, $112-123$. https://doi.org/10.1016/j.tmp.2016.08.003

Putnam, R. (2006). Comunidade e democracia: a experiência da Itália moderna. Rio de Janeiro: FGV.

Rovere, M. (1999). Redes en Salud: un Nuevo paradigm para el abordage de las organizaciones y la comunidade Rosario. Rosario: AMR.

Schenkel, E. \& Almeida, F. (2015). The 2001 economic crisis in Argentina and its repercussions on tourism policy. Tourism Today, 78-89.

Seki, K. (2013). A study on the process of regional tourism management in collaborations between public and private sectors. Transactions on Ecology and The Environment, 1, 339-349.

Schenkel, E., \& Almeida, F. (2015). The 2001 Economic crisis in Argentina and its repercussions on tourism policy. Tourism Today, (July), 78-89.

Tang, X. (2017) The historical evolution of China's tourism development policies (1949-2013) - A quantitative research approach. Tourism Management, 58, 259-269. https://doi.org/10.1016/j.tourman.2016.03.010

Tineo, D \& Tomazzoni, E. (2017). Santos e região convention \& visitors bureau e a governance para o desenvolvimento turístico da costa da Mata Atlântica (SP). Caderno Virtual de Turismo, 17(3), 113-130. http://dx.doi.org/10.18472/cvt.17n3.2017.1195

Tretin, F. (2016). Governança turística em destinos brasileiros: comparação entre Armação dos Búzios/RJ, Paraty/RJ e Bonito/MS. Pasos, 14(3), 645-658.

Urano, D.; Siqueira, F. \& Nóbrega, W. (2016). Articulação em redes como um processo de construção de significado para o fortalecimento do turismo de base comunitária. Caderno Virtual de Turismo, 16 (2), 200 210. http://dx.doi.org/10.18472/cvt.16n2.2016.1173

Velasco González, M. (2010). Gobernanza del turismo: retos y estrategias de las redes de destinos turísticos. XV Congreso AECIT Dinámicas de Transformación Del Turismo En EI Siglo XXI, 1-13. Retrieved from http://www.aecit.org/uploads/public/congresos/15/C15.pdf

Velasco Gonzalez, M. (2013). Gestión pública Del turismo. La gobernanza. In Fernández, J. \& Sánchez, Y. (Eds.). Gestión estratégica sostenible de destinos turísticos. Sevilla: Universidad Internacional de Andalucía.

Velasco Gonzalez, M. \& Tretin, F. (2014). Evolução da política de turismo no Brasil e España: enfoque nas redes de atores. $V$ Congresso Internacional em Gobierno, Administración y Políticas Públicas. Madrid, España. GIGAPP - Grupo de Investigación em Gobierno, Administración y Políticas Públicas.

Valente, F.; Dredge, D. \& Lohmann, G. (2015). Leadership and governance in regional tourism. Journal of Destination Marketing \& Management, 4(2), 127-136. https://doi.org/10.1016/i.jdmm.2015.03.005

Wan, Y. \& Bramwell, B. (2015). Political economy and the emergence of a hybrid mode of governance of tourism planning. Tourism Management. 50, 316-327. https://doi.org/10.1016/i.tourman.2015.03.010 


\section{Informações dos autores}

\section{Ana Catarina Alves Coutinho}

Doutoranda do Programa de Pós-Graduação em Turismo na Universidade Federal do Rio Grande do Norte (UFRN/PPGTUR). Docente na Universidade Federal do Maranhão/Campus São Bernardo (UFMA).

Contribuição na pesquisa: Concepção da pesquisa, revisão da literatura, coleta de dados, análise de dados, discussão. E-mail: coutinho.catarina1@gmail.com

ORCID: https://orcid.org/0000-0001-6654-6629

Wilker Ricardo de Mendonça Nóbrega

Doutor em Ciências Sócio Ambientais pela Universidade Federal do Pará - NAEA / UFPA. Docente da Universidade Federal do Rio Grande do Norte (UFRN).

Contribuição na pesquisa: Concepção da pesquisa, revisão da literatura, coleta de dados, análise de dados, discussão.

E-mail: wilkernobrega@yahoo.com.br

ORCID: https://orcid.org/0000-0002-1628-3493 